\title{
Gestão de Unidades de Conservação: um estudo de caso na Área de Proteção Ambiental da Serra de Baturité-CE
}

\section{Management of Protected Areas: a case study in the Environmental Protection Area of the Sierra de Baturité-CE}

\section{Jaqueline Silva ${ }^{1}$, Maria das Graças Vieira ${ }^{2}$, Gustavo Veras ${ }^{3}$}

${ }^{1}$ Administradora - Universidade Federal de Pernambuco (UFPE).

${ }^{2}$ Doutora em Educação e Professora da Universidade Federal de Pernambuco (UFPE).

${ }^{3}$ Geógrafo, Universidade Federal de Pernambuco (UFPE), Fiscal Ambiental da

Superintendência Estadual do Meio Ambiente (SEMACE). E-mail:

gustavo.antonio@semace.ce.gov.br.

Resumo. O objetivo deste estudo foi analisar a gestão de uma unidade de conservação, localizada no Estado do Ceará. O estudo é de natureza qualitativa, o método utilizado foi o estudo de caso e como instrumento de coleta de dados, realizou-se uma entrevista semiestruturada com a gerência da área. De acordo com as informações obtidas por meio dos instrumentos de pesquisa concluiu-se que a gestão da área está se reestruturando. Resultados positivos foram observados, no entanto, algumas variáveis gerenciais, como o aumento do quadro funcional, precisam ser reformuladas.

Palavras-chave: Unidades de Conservação; planejamento; gestão; área de Recebido: 12/10/2014

Aceito: $14 / 10 / 2014$

Publicado: 20/11/2014 proteção ambiental.

\begin{abstract}
The aim of this study was to study aims to examine the management of a protected area, located in the state of Ceará. The study is qualitative in nature, the method used was the case study and as a tool for data collection, there was a semi-structured interview with the management of the area. According to information obtained by means of the research concluded that the management of the area is restructuring. Positive results were observed, however, some managerial variables, such as increasing the workforce, need to be reformulated.
\end{abstract}

Keywords: Conservation units; planning; management; environmental protection area.

\section{Introdução}

A história evolutiva da sociedade mostra que a ação do homem no planeta tem sido extremamente modificadora, levando em consideração a degradação e a exaustão da maior parte das riquezas naturais e dos bens ambientais.

Ante o atual (e perverso) padrão de produção e consumo, começa a surgir um maior interesse pela temática ambiental, temática essa que assume cada vez mais espaço nas discussões cotidianas, nas atitudes e comportamento das pessoas, na mídia, nos negócios, na educação, nas teses acadêmicas. Enfim, as pessoas começaram a despertar para a necessidade de uma agenda ambiental mais incisiva e eficiente.

Segundo Barbieri (2007), a administração, gestão do meio ambiente ou simplesmente gestão ambiental, podem ser entendidas como as diretrizes e as diligências administrativas e operacionais, entre elas o planejamento, a alocação de recursos, a direção, o controle e outras. Essas atividades tem por objetivo, alcançar resultados positivos relacionados ao meio ambiente, diminuindo ou eliminando os problemas causados pela ação humana ou impedindo que eles surjam.

A categoria Área de Proteção Ambiental (APA) possui previsão legal no di- 
ploma que institui o Sistema Nacional de Unidades de Conservação da Natureza, a Lei Federal $n^{\circ}$ 9.985/2000 (Paz et al., 2006). Dentro da subdivisão entre UCs, insere-se no grupo das unidades de conservação de uso sustentável que tem como objetivo a compatibilização entre a conservação da Natureza e o uso sustentável de parcela dos seus recursos naturais. De acordo com o art. 15 da referida lei a APA tratase "de uma área extensa, com certo grau de ocupação humana, dotada de atributos abióticos, bióticos, estéticos ou culturais especialmente importantes para a qualidade de vida e o bem-estar das populações humanas" (Brasil, 2000).

O foco deste trabalho foi estudar sob a perspectiva da ciência administrativa, a gestão de uma unidade de conservação localizada no Estado do Ceará. A Área de Proteção Ambiental da Serra de Baturité, criada pelo Governo do Estado do Ceará foi instituída através do Decreto Estadual $\mathrm{n}^{\circ}$ 20.956, de 18 de setembro de 1990.

\section{Unidades de Conservação}

A criação e a manutenção de Unidades de Conservação é uma estratégia mundialmente consagrada para a conservação da biodiversidade. No contexto mundial são várias as formas de proteção. As áreas protegidas diferenciam-se entre si em relação à finalidade, ao nível de intervenção do homem na natureza e à esfera de gestão (governamental e privada). Nesse cenário, o surgimento dos termos áreas protegidas (protected areas) ou área silvestre (wilderness) deu-se com a criação do Parque Nacional de Yellowstone nos Estados Unidos, em 1872. Este, inserido num contexto de grande beleza cênica, com o objetivo de proibir qualquer exploração que alterasse as características naturais da área, destinandoa para a preservação, lazer e benefício das gerações futuras. Baseando-se na iniciativa americana, outros países iniciaram o processo de criação de áreas protegidas: Canadá (1885), Nova Zelândia (1894), África do Sul e Austrália (1898), México (1894), entre outros (Côrte, 1997).

Percebe-se que o surgimento dessas áreas tanto no cenário internacional, quanto no nacional, aconteceu muito antes do que imaginamos. No Brasil, apesar de terem existido alguns esforços para a criação de áreas protegidas no período citado anteriormente, somente em 1937 foi criado o primeiro Parque Nacional do Brasil, o do Itatiaia (Paz et al., 2006). Esse parque, criado com base no Código Florestal de 1934, tinha como objetivo atender as finalidades de pesquisa científica e a demanda turística. Na verdade, os primeiros Parques Nacionais brasileiros tiveram como mola propulsora 0 objetivo de criar verdadeiros monumentos públicos naturais, com área delimitada para preservar parte significativa de ecossistemas que tivessem, ao mesmo tempo, valor científico e beleza cênica (Ramos, 2012).

A delimitação de áreas prioritárias, dentro do território nacional, para o estabelecimento de tutelas ambientais restritas tem sido uma importante ferramenta da gestão ambiental na esfera governamental. Atualmente, a norma jurídica brasileira que trata especificamente acerca de Unidades de Conservação é a Lei Federal no 9.985/2000, que estabeleceu o Sistema Nacional de Unidades de Conservação (SNUC).

Apesar de constituírem em importantes instrumentos de conservação da biodiversidade, as Unidades de Conservação muitas vezes não alcançam o objetivo para a qual foram criadas, pois: "somente a criação de unidades de conservação não é suficiente para assegurar o patrimônio natural e cultural de uma nação” (Debetir, 2006, p. 1).

Um tema constante nas estratégias de estabelecimento de um sistema gerencial de UCs, é que seja ecologicamente representativo e efetivamente manejado, a avaliação da efetividade da gestão é uma ferramenta importante para a identificação da situação atual de UCs e/ou do sistema de UCs.

\section{O Sistema Nacional de Unidades de Con- servação}

As áreas protegidas brasileiras foram regidas, inicialmente pelo Código Florestal de 1934, que previa a existência de parques e de diversos tipos de florestas. $\mathrm{O}$ Código Florestal de 1965 já previa as UCs, de uso indireto (parques nacionais, estaduais, municipais e reservas biológicas), que não permitam o uso dos recursos naturais, e de uso direto (florestas nacionais, estaduais e municipais e parques de caça), que permi- 
tam a exploração direta dos recursos naturais. Além disso, previa outros dois tipos de áreas protegidas, que não eram UCs: Áreas de Preservação Permanente (APP) e Áreas de Reservas Legais (ARL). Independentemente do Código Florestal de 1965, uma variedade grande de UCs, com denominações e finalidades diversas, foi sendo criada nas esferas de governo federal, estadual e municipal.

A situação exigia um esforço de sistematização. Assim, o objetivo específico da Lei do SNUC foi estabelecer critérios e normas para a criação, implantação e gestão das UCs. A lei ensejou um movimento no sentido da padronização e da organização das categorias de manejo, bem como de gestão integrada das UCs.

A Lei $n^{\circ} 9.985 / 2000$, que instituiu o Sistema Nacional de unidades de Conservação da Natureza - SNUC veio para fornecer um fundamento legal ao estabelecimento e à gestão das unidades de conservação, bem como para regulamentar o $\S 1^{\circ}$, I, II, III e VII, do art. 225, da Constituição Federal de 1988.

A maior preocupação da Lei $\mathrm{n}^{\circ}$ 9.985/2000 foi tentar dar sistematicidade ao modelo de unidades de conservação brasileiro, que até mesmo por uma lacuna legislativa nunca operou de forma organizada (Benjamin, 2001). De outro modo, a Lei do SNUC não cria unidades de conservação, apenas estabelece medidas de forma sistêmica para tanto, sendo uma norma geral sobre a qual devem se orientar as demais (Derani, 2001).

A criação de unidades de conservação exige a matéria (Natureza), o agente (Poder Público) e os meios/instrumentos (os fatores). Como principais fatores necessários à criação dessas unidades, podem ser destacados os objetivos, as diretrizes e a estrutura a ser implantada (Milaré, 2009, p. 697).

A Lei $n^{\circ} 9.985 / 2000$ traz em seu art. $4^{\circ}$ os objetivos do Sistema Nacional de Unidades de Conservação da Natureza SNUC, que além de seu conteúdo ecológico de grande alcance, abrangendo a biodiversidade, os elementos da hidrosfera e da litosfera, enfatizam a necessidade de promover o desenvolvimento sustentável como forma de harmonizar os interesses econômico-sociais e a integridade do meio ambi- ente. A importância desses princípios é revelada também, através do enfoque dado à educação ambiental e às comunidades tradicionais, necessitando estas de proteção em razão de sua vulnerabilidade.

\section{Diretrizes do SNUC}

No que concerne às diretrizes estabelecidas para o SNUC, Milaré (2009) afirma que estas representam a linha orientadora a ser seguida de forma a tornar viável o desenvolvimento das unidades de conservação e o alcance de seus objetivos, merecendo destaque a exigência de mecanismos e procedimentos que assegurem o envolvimento da sociedade, a participação efetiva das populações locais. Levando-se em consideração as suas necessidades, no uso sustentável dos recursos naturais, os meios de subsistência às populações tradicionais, pois estas representam um importante aliado para a proteção do meio ambiente e a sustentabilidade econômica das unidades de conservação. A obediência a esse norte estabelecido significa condição necessária para que o Sistema Nacional de unidades de Conservação da Natureza - SNUC mantenha-se de forma eficaz.

\section{Gestão de Unidades de Conservação}

Atualmente há muita polêmica ou mesmo um certo desentendimento em torno dos termos que designam as atividades desenvolvidas em uma unidade de conservação. Os termos administração, manejo e gestão ganharam popularidade, mas ainda que sejam usados de forma semântica guardam similaridades e diferenças importantes. Na verdade, com origem no termo inglês "management", os três termos citados acima tendem a significar em português o ato de dirigir, governar ou manusear com as mãos (Côrte 1997, p. 66).

Ainda para Côrte (1997, p. 66), o manejo deve ser sempre considerado, como "o conjunto de ações e atividades necessárias ao alcance dos objetivos de conservação e manejo das áreas protegidas; ou seja, em um sentido técnico, as atividades fins”, sendo estas as atividades que dizem respeito ao manuseio, controle ou direção de processos nas unidades de conservação, tais como proteção, recreação, educação, pesquisa e manejo de recursos. Estas atividades são 
especificadas segundo os objetivos da unidade de conservação no Plano de Manejo.

Araújo (2009), ao chamar a atenção para a compreensão sobre as UCs como espaços organizacionais, destaca que a gestão das UCs brasileiras se caracteriza pela ênfase nos aspectos técnicos, com forte concentração nas tarefas a serem desempenhadas, nas instalações físicas, nos equipamentos e instrumentos utilizados, nas técnicas operacionais e no ambiente físico. $\mathrm{O}$ aspecto social - composto pelo conjunto de pessoas, suas habilidades, competências e compreensão acerca do trabalho a ser desenvolvido - é pouco considerado e às vezes negligenciado no processo de gestão de UC. Ainda segundo Araújo (2009), isto é um grande equivoco, pois a baixa efetividade das UCs é explicada por deficiências no âmbito da cultura organizacional da gestão.

Oliveira (2009, p. 35) define a gestão de áreas protegidas como um processo, uma sequência de decisões e ações que resultam de uma reflexão que relaciona presente e futuro - uma busca que tem a interação de antecipar/prever os acontecimentos para então potencializá-los em uma determinada direção. Dentre as ações necessárias à gestão, Oliveira (2009, p. 35) destaca a importância do planejamento, tanto como método, como quanto processo e de seu instrumento mais importante: o plano de manejo. A este, soma-se outros instrumentos importantes no processo de gestão orientado à conservação: os planos de conservação de espécies, planos de prevenção de riscos, planos de monitoramento e avaliação e os planos de gestão ambiental.

\section{As Unidades de Conservação do Ceará}

Menezes et al. (2010), mostram que

a primeira área protegida criada no Ceará foi a Floresta Nacional do Araripe, no ano de 1946, e até o ano de 1989, foram criadas apenas mais 6 (seis) áreas protegidas no estado. A média de criação deste período é de uma área protegida a cada 6 anos. No entanto, a partir de 1990, tem início um grande aumento no número de áreas protegidas no Ceará, com a criação de 75 áreas protegidas no período de 1990 a 2010.

De acordo com levantamento feito por Menezes et al. (2010), o Estado do Ceará conta com 81 áreas protegidas das mais variadas categorias de manejo, incluindo sete Reservas Particulares do Patrimônio Natural (RPPN). Dentro desse quantitativo, estão inseridas 23 UCs estaduais que são gerenciadas pelo Conselho de Políticas e Gestão do Meio Ambiente (Conpam), através da Coordenadoria de Biodiversidade (Cobio). Segundo Conpam 2013, ainda existem mais quatro UCs administradas pela Universidade Regional do Cariri (URCA), de acordo com o Decreto Estadual $n^{\circ}$ 28.506, de $1^{\circ}$ de dezembro de 2006 .

O somatório dessas 81 áreas protegidas inventariadas abrangem 1.131.943,19 ha no Ceará, que em termos proporcionais, corresponde a apenas $7,75 \%$ da área do estado. Menezes, et al. (2010), alertam ao fato de que esse percentual é muito baixo quando se considera as recomendações de especialistas da área de conservação, em que pelo menos cerca de $25 \%$ dos territórios deve estar sob regime de proteção ambiental. Para atingir essa recomendação mínima, o Ceará necessitará triplicar área atualmente protegida, atingindo pouco mais que 3 milhões de hectares em regime de proteção.

Nesse sentido, há dois fatos importantes a serem considerados: primeiro, que essas áreas contemplam apenas $7,7 \%$ do território do Estado (os demais 92,3\% estão completamente desprotegidos); segundo, maior parte da área protegida do Estado encontra-se em regime de uso sustentável, que permite a exploração de recursos ambientais.

A gestão das UCs estaduais antes de responsabilidade da SEMACE, passou a ser desempenhada pelo CONPAM através da criação da COBIO e em conformidade com o que prevê a Lei Estadual $\mathrm{n}^{\circ}$ 14.390/2009, que instituiu o Sistema Estadual de Unidades de Conservação do Ceará (SEUC). Essa transição de responsabilidade gerou uma reorganização do setor ambiental e desenvolveu um contato mais direto com a população. Atualmente o CONPAM tem direcionado esforços para promover a estruturação destas unidades de conservação, com o objetivo de alavancar o fluxo turístico e desenvolver pesquisas técnicas voltadas para o setor ambiental. A SEMACE continua com suas atribuições de execução das políticas ambientais, licenciamento, monitoramento e fiscalização. 


\section{A categoria Área de Proteção Ambiental} (APA)

A categoria Área de Proteção Ambiental (APA) possui previsão legal no diploma que institui o Sistema Nacional de Unidades de Conservação da Natureza, a Lei $n^{\circ} 9.985 / 2000$. Dentro da subdivisão entre UCs, insere-se no grupo das unidades de conservação de uso sustentável e de acordo com o art. 15, da referida lei, tratase "de uma área extensa, com certo grau de ocupação humana, dotada de atributos abióticos, bióticos, estéticos ou culturais especialmente importantes para a qualidade de vida e o bem-estar das populações humanas" (Brasil, 2000).

Segundo a legislação que a conceitua, a APA tem como objetivos básicos proteger a diversidade biológica, disciplinar o processo de ocupação e assegurar a sustentabilidade do uso dos recursos naturais. Diferente de algumas categorias de unidades, a APA pode ser composta por terras públicas e privadas. Um fato interessante a ser observado é que na instituição das APAs não existe a desapropriação de área, permitindo assim que as terras particulares permaneçam sob o domínio de seus proprietários, sendo, obviamente submetidos às regras e ditames legais impostos a unidade, como a ordenação do uso e ocupação do solo.

De acordo com Cabral (2002, p. 43), no Brasil, a categoria Área de Proteção Ambiental é singular, não existindo no mundo qualquer tipo ou categoria que se iguale aos objetivos de criação de uma APA. A autora afirma que considerando que esta é uma unidade de uso sustentável (conservação), podendo ser instituída em terras públicas ou privadas (geralmente há coexistência de ambas), estas terras devem ser manejadas pelos seus proprietários desde que obedeçam a medidas restritivas impostas pelo poder público no sentido de garantir a conservação dos atributos que motivam sua criação e, ainda, gerenciada por meio de Conselho Gestor que pode funcionar como um fórum de debates no qual os conflitos existentes sejam equacionados.

Por permitirem atividades econômicas em seu interior, deve-se incentivar comportamentos de conservação dos recursos pelos proprietários das terras em APAs, sejam estes públicos ou privados. Cabral
(2002, p. 44), esclarece que o desfio é balancear os interesses individuais nesse tipo de espaço protegido, como forma de possibilitar a proteção dos ecossistemas e reforça que para isso ocorra, a atenção deve estar voltada para a gestão desses interesses e das atividades, de maneira que os proprietários, impulsionados por motivações individuais, optem pelo comportamento de conservação dos recursos.

Dotadas, quase sempre, de significativa beleza cênica, as APAs têm se tornado pontos de atração turística e esta atividade tem conquistado espaço diante da tendência atual de valorização do ecoturismo, porém deve-se direcionar uma maior atenção para os problemas causados pela atividade turística desordenada. Em uma APA, acontecem e podem acontecer todas as atividades que a ação humana demandar. $\mathrm{O}$ que deveria determinar o nível das restrições de uso é a capacidade de suporte da área. Então, teoricamente, acredita-se que, o que se deveria limitar não é tanto "o que" fazer, mas "o como" e/ou "o quanto" fazer (Côrte 1997, p. 36).

\section{Metodologia}

Tomando-se por base a classificação utilizada por Lakatos (2011) para a classificação de pesquisas, pode-se afirmar que o presente estudo é fundamentalmente de natureza exploratória, descritiva e qualitativa.

Para a presente pesquisa, utilizou-se de dois tipos de delineamentos básicos: a pesquisa documental e o estudo de caso de natureza qualitativa.

A pesquisa documental foi realizada através da coleta de dados junto a gerência da área estudada, utilizando-se de meios impressos e eletrônicos, como relatórios, material de apoio administrativo e material de suporte as reuniões.

O método para analisar a gestão na Área de Proteção Ambiental da Serra de Baturité, caracteriza-se como estudo de caso. O estudo de caso abrange o estudo profundo e exaustivo de um ou poucos objetos de modo que se permita o seu vasto e detalhado conhecimento (Gil, 1991).

A pesquisa buscou evidenciar as potencialidades e dificuldades existentes na gestão de uma unidade de conservação am- 
biental localizada no Estado Ceará. Para tanto, optou-se fazer uma entrevista com a gerência da APA da Serra de Baturité, com o intuito de obter o maior número possível de informações válidas. A entrevista foi realizada com a assessora do gestor da área, que trabalha no local desde 2005, possuindo experiência e conhecimento das suas questões gerenciais. A referida entrevista consta de 16 perguntas que foram compostas por assuntos pertinentes ao tema em estudo e não seguiram uma sequência lógica de elaboração.

Os dados coletados através desses instrumentos junto ao universo da pesquisa sucederam durante o mês de janeiro e fevereiro de 2013, sendo a coleta realizada junto à gerência da área, através de visitas previamente agendadas. Ao final desta etapa, as informações coletadas junto à gerência foram organizadas e analisadas, a fim de iniciar um estudo de forma mais detalhada, no intuito de definir quais as potencialidades e dificuldades existentes na gestão da APA.

Para analisar os dados obtidos, todas as informações alcançadas por meio da aplicação dos instrumentos de pesquisa foram agrupadas e esquematizadas de forma planejada para facilitar o desenvolvimento da pesquisa e o processo de análise (Andrade, 2006).

\section{Resultados e Discussão}

A APA da Serra de Baturité, a primeira e mais extensa Área de Proteção Ambiental criada pelo Governo do Estado do Ceará, estabelecida por meio do Decreto Estadual $\mathrm{n}^{\circ}$ 20.956, de 18 de setembro de 1990, compreende uma área de 32.690 ha e localiza-se na porção Nordeste do Estado, na região serrana do Maciço de Baturité.

Delimitada pela cota $600 \mathrm{~m}$ é composta pelos Municípios de Aratuba, Baturité, Capistrano, Guaramiranga, Mulungu, Pacoti, Palmácia e Redenção. Está situada a $90 \mathrm{~km}$ da Capital Fortaleza, tendo como principais acessos, partindo de Fortaleza, a Rodovia CE-060, sentido PacatubaBaturité, e a Rodovia CE-065, sentido Maranguape-Palmácia.

Segundo Silva (2011, p. 14), a referida UC, apesar de todas as dificuldades pelas quais tem passado a efetivação de suas atribuições legais, tem promovido, sem sombra de dúvidas, a conservação e preservação dos atributos naturais nela contidos. Certamente, o caminho a ser percorrido ainda se apresenta longo. Entretanto, os ganhos com a conservação são inegáveis. Este ganho só não é maior devido ao fato de que a lacuna existente entre $o$ ato de criação e a real implementação das atribuições legais para a preservação da biodiversidade nas Unidades de Conservação, ainda ser muito grande. Em outras palavras, ainda existe uma grande distância entre criar uma Unidade de Conservação e garantir o seu efetivo manejo.

De acordo com Silva (2011, p. 37), os problemas enfrentados para uma real preservação dos atributos naturais da APA de Baturité ainda são muitos. A insuficiência de pessoal qualificado e de infraestrutura básica é uma das maiores dificuldades. A deficiência na formação de uma consciência ambiental mais consistente, através de programas educativos específicos, também se constitui num grande entrave à implantação do desenvolvimento sustentável no território da APA.

Além disso, a implantação de empreendimentos turísticos e a divisão de grandes glebas de terras entre famílias têm pressionado negativamente o ecossistema da Serra de Baturité. A abertura de novas vias de acesso e o alargamento e pavimentação de outras, poderá, a curto e médio prazo, contribuir para a destruição da biota local, uma vez que proporcionará um fluxo maior de pessoas o que, fatalmente, aumentará o consumo de recursos naturais e, da mesma forma, fará crescer os níveis de poluição e degradação. Outro problema enfrentado se refere a falta de articulação política entre as diversas esferas de governo e as entidades públicas e civis envolvidas na preservação da APA redunda na falta de eficácia e eficiência necessárias à preservação dos seus atributos naturais (Silva 2011, p. 37).

A APA possui três imóveis, sendo que dois deles são de apoio, e um terceiro onde deveria funcionar o Centro de Referência para o Desenvolvimento Sustentável. O primeiro prédio consiste no Sítio Cocão, que está localizado no município de Guaramiranga, na estrada que vai para a localidade denominada Pico Alto, 
o imóvel possui um terreno de 69 ha, conta com uma sede e atualmente com vigilância 24 horas. Tal sede foi inaugurada no final do ano de 2006 e até então não funcionou, segundo relato contido em Relatório Técnico da APA.

Quanto ao prédio onde funciona a sede da unidade de conservação, o local situa-se no Sítio Granja, Município de Pacoti, e conta com infraestrutura para albergar o supervisor da APA, setor de educação ambiental, sala para reuniões e escritório para assuntos administrativos, equipado com infraestrutura para funcionamento, possui também um horto florestal, onde há a produção, controle e manutenção das mudas, bem como a distribuição aos interessados.

O outro imóvel trata-se de um terreno de 157 ha localizado no Sítio Batalha, Município de Guaramiranga. O local foi inaugurado em 2005 para ser um centro de referência para o desenvolvimento sustentável. A proposta inicial era de que o local seria uma unidade demonstrativa de tecnologias alternativas, como a agricultura orgânica e o sistema agroflorestal. No local deveria funcionar também um centro de informação ambiental, com visitas as trilhas de interpretação ambiental. Atualmente apenas uma trilha está funcionando, as outras necessitam de manutenção e monitores capacitados para receber e orientar os visitantes.

Torna-se urgente a conservação e a manutenção das edificações de apoio, além da aquisição de materiais necessários à conservação e à manutenção das instalações elétricas, eletrônicas, hidrossanitárias, de voz e dados e demais instalações dos prédios. Tais atos devem ser norteados pela gestão participativa, redução de custos e manutenção preventiva em detrimento da corretiva. Sugere-se também serem desenvolvidos programas de conservação da água e energia elétrica, bem como programa de descarte inteligente das lâmpadas.

\section{Gestão Administrativa e Financeira}

Os recursos para a gestão da APA provém atualmente em sua integralidade do Conselho de Políticas e Gestão do Meio Ambiente (CONPAM) órgão responsável pela implementação e gerenciamento de todas as UC's estaduais. No entanto, observou-se a ausência de um banco de dados com o balanço financeiro da UC. Este problema se estende também para as informações gerenciais, pois nas gestões anteriores não havia a preocupação e comprometimento de registrar a rotina administrativa e ações desenvolvidas na APA.

De acordo com as informações coletadas através da entrevista semiestruturada, para a consolidação da gestão da unidade de conservação foram firmadas algumas parcerias entre o órgão gestor e algumas entidades, dentre as quais se destacam: a Associação de Pesquisa e Preservação de Ecossistemas Aquáticos (AQUASIS), responsável pela ação de divulgação do projeto periquito da cara suja e por dar apoio logístico; Grupo de Interesse Ambiental (GIA), que realiza ações de educação e conscientização ambiental; Núcleo de Iniciativa Comunitária (NIC), atuando com ações de educação ambiental e capacitação para agricultura ecológica; Associação dos Produtores de Café do Maciço de Baturité (APEMB), através do projeto Café Ecológico; prefeituras da região, colaborando com ações de educação ambiental e plantio de mudas.

\section{Recursos Humanos}

Outro tema de extrema importância para a gestão de unidades de conservação são os recursos humanos. A falta de pessoal, que é agravada pela falta de preparo desses em enfrentar as necessidades das unidades são um dos maiores problemas para o manejo das UCs. Além da questão quantitativa há de atentar-se para a capacitação e motivação dos funcionários que trabalham nestas unidades. Por se tratar de áreas com diversos interesses e conflitos, os recursos humanos de apoio e de gestão devem possuir habilidades e conhecimentos em diversas áreas. Obviamente que o supervisor da unidade deve possuir mais atributos, mas os funcionários de apoio também precisam obter conhecimentos e dispor de uma desenvoltura na gestão. Administração pública e ambiental, gestão ambiental, relações públicas e humanas, legislação ambiental e relacionamento político/institucional são algumas das áreas de formação necessárias para a eficiente gestão (Côrte, 1997, p. 84). 
Durante a realização da pesquisa, o corpo técnico estava composto pelos seguintes servidores: um Supervisor de APA; dois Técnicas de Atendimento; um Vigilante; dois Jardineiros e umAuxiliar de Serviços Educacionais.

Alguns fatores pessoais, tais como flexibilidade, habilidade de comunicação, assertividade, liderança e capacidade de administrar conflitos, também são necessários para o melhor desempenho das atividades.

Quanto à forma de contratação dos servidores, em 2011 o CONPAM promoveu uma seleção pública para selecionar 23 Supervisores de Núcleo (cargo do Gerente da APA). À época era oferecido um salário de $\mathrm{R} \$ 1.347,52$ (um mil trezentos e quarenta e sete reais e cinquenta e dois centavos) pela jornada de 40 horas semanais, com um contrato de dois anos. A seleção foi feita em duas etapas, uma de análise curricular e a outra através de entrevista. Dentre as tarefas do supervisor de núcleo, segundo o Edital $n^{0} 001 / 2011$, estão a obrigatoriedade de participar da elaboração e implantação dos planos de manejo das UCs, realizar inspeção, elaborar diagnóstico e avaliar estudos de impactos ambientais, articular o funcionamento dos conselhos gestores, promover pesquisas e participar de audiências públicas.

Com exceção do supervisor, todos os servidores são terceirizados e possuem vínculo com a empresa CMC Serviços Terceirizados Ltda. No entanto, os Extratos dos Contratos $n^{\circ} 35 / 2012$ e $n^{\circ} 36 / 2012$, ambos publicados no Diário Oficial do Estado (DOE) de 26 de dezembro de 2012, tratam da ação de terceirização de servidores para trabalharem nas Unidades de Conservação de todo o Estado do Ceará. Os dados levantados na pesquisa apontam para a necessidade da contratação de mão de obra mais especializada (Técnicos de Nível Superior) para análises e estudos técnicos mais completos.

\section{Educação Ambiental}

Como solução para frear as ações antrópicas danosas ao meio ambiente, além de outras atividades, existe a Educação Ambiental (EA). De acordo com a Lei $n^{\circ}$ 9.795/1999, entende-se por educação ambiental os processos por meio dos quais o indivíduo e a coletividade constroem valores sociais, conhecimentos, habilidades, atitudes e competências voltadas para a conservação do meio ambiente, bem de uso comum do povo, essencial à sadia qualidade de vida e sua sustentabilidade.

Segundo a Política Nacional de Educação Ambiental (PNEA), todos têm direito a EA e determina que os diferentes agentes envolvidos tenham atribuições na defesa e proteção do meio ambiente. Pois, a educação ambiental só será efetiva se houver uma união e cooperação entre poder público, instituições educativas, meios de comunicação, empresas, entidades de classe e a sociedade como um todo. A educação ambiental possui como mola mestra a disseminação de informações e a participação da população na resolução de problemas, principalmente quando da implantação de mudanças, e só é considerada eficaz na medida em que a população alvo se conscientiza do seu papel como protagonista no meio ambiente e modifica comportamentos indevidos.

De acordo com as informações coletadas durante a pesquisa, as ações de educação ambiental na APA contam com um calendário anual de atividades. A Semana do Meio Ambiente, Semana de Reflorestamento da APA, Semana da Árvore e Dia Nacional de Limpeza de Praias, Rios, Lagos e Lagoas. Em 2012, segundo o relatório de atividades de gestão, a Semana de Reflorestamento da APA atendeu aos Municípios de Barreira, Redenção, Baturité, Pacoti, Aratuba, Guaramiranga e Palmácia. Atingindo um público de aproximadamente 800 pessoas, formado essencialmente por: agricultores, professores, alunos da rede pública estadual e municipal, universitários, funcionários públicos, associações e sindicatos. Quanto aos recursos materiais para tais atividades a gerência da APA possui apoio da Casa Civil do governo do Estado que cede stand e tenda para as ações e conta também com apoio do setor de educação ambiental do CONPAM que fornece material e recursos humanos para as campanhas.

Através das experiências relatadas durante a pesquisa, percebe-se que a EA tem grande potencial de gerar bons frutos para as UCs, mas exige tempo, dedicação e continuidade. Esses fatores, muitas vezes, desestimulam um gestor de iniciar progra- 


\begin{tabular}{|c|c|c|}
\hline \multirow[b]{3}{*}{$\begin{array}{l}\text { Forças } \\
\text { Restritivas }\end{array}$} & Ambiente Interno & Ambiente Externo \\
\hline & Pontos fracos & Ameaças \\
\hline & $\begin{array}{l}\text { - Ausência do Plano de Manejo. } \\
\text { - Dificuldades na comunicação } \\
\text { por telefonia, rádio e Internet. } \\
\text { - Informações dispersas ou } \\
\text { inacessíveis sobre a gestão. } \\
\text { - Falta de assiduidade às reuniões } \\
\text { do conselho consultivo. } \\
\text { - Rotatividade de gerentes. } \\
\text { - Deficiência quantitativa e } \\
\text { qualitativa de recursos humanos. } \\
\text { - Ausência de um banco de dados } \\
\text { com o balanço financeiro e/ou } \\
\text { gerencial da UC. }\end{array}$ & $\begin{array}{l}\text { - Falta de um programa de voluntariado. } \\
\text { - Distanciamento da população local com } \\
\text { o órgão gestor. } \\
\text { - Falta de uma equipe de fiscalização } \\
\text { ambiental fixa. } \\
\text { - Imagem (atuação) do órgão não é } \\
\text { totalmente clara para a comunidade, com } \\
\text { imagem fragmentada e baixa percepção da } \\
\text { população local. } \\
\text { - Precariedade da sinalização ambiental. } \\
\text { - Trilhas mal conservadas. } \\
\text { - Turismo desordenado. }\end{array}$ \\
\hline \multirow[b]{2}{*}{$\begin{array}{l}\text { Forças } \\
\text { Impulsoras }\end{array}$} & Pontos Fortes & Oportunidades \\
\hline & $\begin{array}{l}\text { - Boa infraestrutura física, com } \\
\text { equipamentos relativamente } \\
\text { novos. } \\
\text { - Serviço de manutenção e apoio } \\
\text { terceirizado com o fornecimento } \\
\text { de mão-de-obra } \\
\text { - Reuniões periódicas do } \\
\text { Conselho Consultivo } \\
\text { - Calendário anual de ações de } \\
\text { educação ambiental } \\
\text { - Parceria com ONGs para a } \\
\text { proteção do meio ambiente. }\end{array}$ & $\begin{array}{l}\text { - Possibilidade de se estabelecer termos de } \\
\text { cooperação técnica entre o órgão gestor e } \\
\text { universidades. } \\
\text { - Estabelecer um contato direto com a } \\
\text { população local promovendo ações de } \\
\text { educação ambiental voltadas } \\
\text { exclusivamente para esse público. } \\
\text { - Estreitar a relação com os demais órgãos } \\
\text { ambientais. } \\
\text { - Desenvolver ações de ecoturismo na } \\
\text { área. } \\
\text { - Melhorar a sinalização ambiental }\end{array}$ \\
\hline
\end{tabular}

Fonte: Adaptado de Silva (2009).

Figura 1. Análise Situacional Estratégica da Gestão.

mas nas áreas para as quais trabalha. No entanto, com as crescentes pressões que a maioria das UCs enfrenta, este é um caminho que merece ser priorizado, pois pode trazer apoio à própria conservação. Uma vez que a educação ambiental tem toda uma legislação a seu favor, com objetivos claros, o gestor pode se alicerçar nos argumentos legais para desenvolver programas nas UCs para as quais é responsável. Os desafios podem ser muitos, inclusive a capacitação de uma equipe apta a desenvolver trabalhos nesse campo.
Análise Situacional e Estratégica da Gestão

Depois de fazer o levantamento de dados, pode-se então, cruzar as informações, para que, dessa maneira, seja possível encontrar alternativas para a sua operação de negócios. Combinando fatores externos e internos podemos avaliar como suas forças podem servir como impulso para aproveitar as oportunidades, ou, ainda, saber como deve se reposicionar em relação às fraquezas para não sofrer as consequências das ameaças encontradas. 
A matriz SWOT a seguir (Figura 1), sintetiza as Forças Restritivas (Pontos Fracos e Ameaças) e as Impulsoras (Pontos Fortes e Oportunidades), considerando o ambiente interno e externo da área estudada. A partir das variáveis gerenciais levantadas através da análise, a equipe gerencial da área poderá usá-las como embasamento para o desenvolvimento de ações de correção e melhoria, se assim achar oportuno.

\section{Conclusões}

Os resultados da pesquisa apontaram que a gestão da área passou por um momento de transição entre órgãos responsáveis por esta. Com isso, a gestão das UCs estaduais ainda está em fase de reestruturação. As ações desenvolvidas na APA no último ano apontam para uma melhoria considerável em sua gestão. No entanto, a falta de recursos humanos e financeiros envolvidos no desenvolvimento e implementação de ações de gestão da APA foi citada, na pesquisa, como a maior dificuldade na gestão da área. Diante dessa deficiência, a gerência acaba por resolver apenas problemas rotineiros e irrisórios perante as reais necessidades da APA.

Foi percebido também que a fiscalização na APA é deficiente atendendo apenas a situações de denúncias e com uma periodicidade quinzenal. A fiscalização não deve ser o alvo principal da unidade gestora da APA, esta deve se ocupar mais com a execução de programas preventivos do que repressivos. A atividade de fiscalização se possível, deve ser delegada a outro órgão e é o que acontece na área estudada. No entanto, considerando sua extensão e as demandas cotidianas, a hipótese de uma equipe de fiscalização permanente não deve ser descartada.

O conhecimento interdisciplinar de todos os aspectos relativos à área em questão, torna-se instrumento essencial no estabelecimento de estratégias de atuação para o cenário almejado. Isto se aplica em todos os processos de planejamento e, portanto, também na gestão ambiental. A diferença está no fato de que na gestão ambiental se "dirige" todo o ecossistema em questão, tornando a ação mais complexa, exigente do ponto de vista técnico e de muita responsabilidade. Talvez por isso, muitas vezes tem-se tomado uma atitude passiva de dei- xar as unidades de conservação sem nenhuma intervenção efetiva.

Por outro lado, essas ausências teóricas, metodológicas e reflexivas que podem não serem encontradas neste trabalho, ou ainda, que são percebidas de maneira incompleta, poderão ser utilizadas futuramente como portas de entrada para estudos semelhantes a este. Nesse sentido, as deficiências presentes aqui podem futuramente serem realocadas e conduzidas a outras análises ou mesmo vir a contribuir em outros momentos, significativamente com os propósitos e desenvolvimento desta pesquisa.

\section{Referências}

Andrade, M. M. Introdução à metodologia do trabalho científico. 7. ed. São Paulo: Atlas, 2006.

Araújo, M. A. R. Melhorando a efetividade da gestão de Unidades de Conservação: a experiência do Programa de Gestão para Resultados PGR. Brasília: MMA, 2009. (Cadernos ARPA, 3).

Barbieri, J. C. Gestão ambiental empresarial: conceitos, modelos e instrumentos. 2. ed. São Paulo: Saraiva, 2007.

Benjamin, A. H. Introdução à lei do Sistema Nacional de Unidades de Conservação. In: Benjamin, A. H. (Coord.). Direito ambiental das áreas protegidas: o regime jurídico das Unidades de Conservação. Rio de Janeiro: Forense Universitária, 2001. p. 276-316.

Brasil. Leis, decretos, etc. Constituição da República Federativa do Brasil de 1988. Disponível em: <http://www.planalto.gov.br/ ccivil_03/constituicao/Constituicao.htm>.

Acesso em: 22 mar. 2013.

Brasil. Leis, decretos, etc. Lei $\mathbf{n}^{\mathbf{0}}$ 9.795, de 27 de abril de 1999. Dispõe sobre a educação ambiental, institui a Política Nacional de Educação Ambiental e dá outras providências. Disponível em: <http://www.planalto.gov.br/ ccivil_03/leis/19795.htm>. Acesso em: 22 mar. 2013.

Brasil. Leis, decretos, etc. Lei $\mathbf{n}^{0} \mathbf{9 . 9 8 5}$, de 18 de julho de 2000. Regulamenta o art. 225, § $1^{\circ}$, incisos I, II, III e VII da Constituição Federal, institui o Sistema Nacional de Unidades de Conservação da Natureza e dá outras providências. Disponível em: <http://www.planalto.gov. br/ccivil_03/leis/19985.htm>. Acesso em: 22 mar. 2013.

Brasil. Leis, decretos, etc. Decreto $\mathbf{n}^{\circ} \mathbf{4 . 3 4 0}$, de 22 de agosto de 2002. Regulamenta artigos da 
Lei $n^{\circ}$ 9.985, de 18 de julho de 2000, que dispõe sobre o Sistema Nacional de Unidades de Conservação da Natureza - SNUC, e dá outras providências. Disponível em: <http://www. planalto.gov.br/ccivil_03/decreto/2002/d4340. htm>. Acesso em: 22 mar. 2013.

Ceará. Leis, decretos, etc. Decreto no 20.956, de 18 de setembro de 1990. Disponível em: $<$ http://antigo.semace.ce.gov.br/integracao/ biblioteca/legislacao/conteudo_legislacao.asp? $c d=56>$. Acesso em: 22 mar. 2013.

Ceará. Leis, decretos, etc. Decreto no 27.216, de 17 de outubro de 2003. Dispõe sobre a criação do Conselho Consultivo da Área de Proteção Ambiental da Serra de Baturité. Disponível em: <http://imagens.seplag.ce.gov.br/PDF/ 20031017/do20031017p01.pdf $>$. Acesso em: 22 mar. 2013.

Ceará. Leis, decretos, etc. Decreto $\mathbf{n}^{\mathbf{0}}$ 28.506, de $1^{\circ}$ de dezembro de 2006. Disponível em: $<$ http://imagens.seplag.ce.gov.br/PDF/20061201 /do20061201p01.pdf $>$. Acesso em: 22 mar. 2013.

Ceará. Leis, decretos, etc. Lei $\mathbf{n}^{\mathbf{0}}$ 14.390, de 07 de julho de 2009. Institui o Sistema Estadual de Unidades de Conservação do Ceará - SEUC, e dá outras providências. Disponível em: $<$ http://imagens.seplag.ce.gov.br/PDF/20090709 /do20090709p01.pdf $>$. Acesso em: 22 mar. 2013.

Conpam. Conselho de Políticas e Gestão do Meio Ambiente. Unidades de Conservação. Disponível em: <http://www.conpam.ce.gov.br/ index.php?option=com_content\&view=article\& id=43458\&Itemid=133>. Acesso em: 15 mar. 2013.

Conpam. Conselho de Políticas e Gestão do Meio Ambiente. Relatório de Atividades - APA da Serra de Baturité. Pacoti: Conpam, 2012.

Cooper, D. R.; Schindler, P. S. Métodos de pesquisa em administração. 7. ed. Porto Alegre: Bookman, 2003.

Debetir, E. Gestão de unidades de conservação sob influência de áreas urbanas: diagnóstico e estratégias de gestão na Ilha de Santa Catarina - Brasil. Florianópolis: UFSC, 2006. (Tese de Doutorado em Engenharia Civil).

Derani, C. Direito ambiental econômico. 2. ed. rev. São Paulo: Max Limonad, 2001a.

Derani, C. A estrutura do Sistema Nacional de Unidades de Conservação - Lei nº 9.985/2000. In: Benjamin, A. H. (Coord.). Direito ambiental das áreas protegidas: o regime jurídico das unidades de conservação. Rio de Janeiro: Forense Universitária, 2001b. p. 232-275.
Gia. Grupo de Interesse Ambiental. Organização não governamental. Disponível em: <http://gia.orgfree.com>. Acesso em: 22 mar. 2013.

Gil, A. C. Como elaborar projetos de pesquisa. São Paulo: Atlas, 1991.

Hair, J. F. Fundamentos de métodos de pesquisa em administração. Porto Alegre: Bookman, 2005.

IBAMA. Instituto Brasileiro dos recursos Naturais Renováveis. Planejamento Biorregional do Maciço de Baturité (Ce). Fortaleza: Instituto Brasileiro dos recursos Naturais Renováveis, Universidade Estadual do Ceará, Banco do Nordeste, 2002.

Malhotra, N. Pesquisa de marketing: uma orientação aplicada. 4. ed. Porto Alegre: Bookman, 2006.

Marconi, M. A.; Lakatos, E. M. Fundamentos de metodologia científica. 7. ed. São Paulo: Atlas, 2011.

Menezes, M. O. T.; Araújo, F. S.; Romero, R. E. O Sistema de Conservação Biológica do Estado do Ceará: diagnóstico e Recomendações. REDE - Revista Eletrônica do Prodema, Fortaleza, v. 5, n.2, p. 7-31, 2010.

Milaré, É. Direito do ambiente: doutrina, prática, jurisprudência, glossário. 2. ed. São Paulo: Revista dos Tribunais, 2009.

Oliveira, D. Avaliação de efetividade de gestão de Unidades de Conservação: o Mosaico do Apuí - Amazonas/AM. Brasília, UnB, 2012. (Dissertação de Mestrado).

Oliveira, M. M. Como fazer pesquisa qualitativa. Petrópolis: Vozes, 2007.

Paz, R. J.; Freitas, G. L.; Souza, E.A. Unidades de conservação no Brasil: história e legislação. João Pessoa: Ed. Universitária/UFPB, 2006.

Ramos, A. Gestão de Unidades de Conservação: compartilhando uma experiência de capacitação. Brasília: WWF-Brasil, 2012.

Seiffert, M. E. B. Gestão Ambiental: instrumentos, esferas de ação e educação ambiental. 2. ed. São Paulo: Editora Atlas, 2011.

SEMACE. Superintendência Estadual do Meio Ambiente do Ceará. Área de Proteção Ambiental da Serra de Baturité. Disponível em: $<$ http://www.semace.ce.gov.br/2010/12/apa-daserra-de-baturite>. Acesso em: 14 mar. 2013.

Silva, L. L. Análise SWOT. Disponível em: $<$ http://agenda-digital.blogspot.com/2009/07/ matriz-de-analise-de-swot.html>. Acesso em: 02 fev. 2013. 